\title{
Characteristics and treatment patterns of patients with type 2 diabetes in Lebanon: the DISCOVER study
}

Sami T. Azar, ${ }^{1}$ Akram Echtay, ${ }^{2}$ Mireille Amm, ${ }^{3}$ Hajar Ballout, ${ }^{3}$ Iskandar Cheaib, ${ }^{3}$ Hicham El Nazer, ${ }^{2}$ Ihab Fardoun, ${ }^{2}$ Ahmad Ghazzawi, ${ }^{2}$ Rafic Kenaan, ${ }^{4}$ Marie Merheb, ${ }^{5}$ Yousef Obeid, ${ }^{2}$ Mounzer Saleh, ${ }^{2}$ Saria Wakim, ${ }^{6}$ Camille Zein ${ }^{2}$ and the DISCOVER study group, Lebanon

${ }^{1}$ Endocrinology Division, Department of Internal Medicine, American University of Beirut Medical Center, Beirut, Lebanon (Correspondence to: Sami

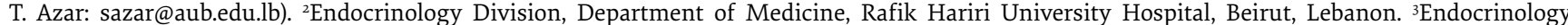
Private Practice, Beirut, Lebanon. ${ }^{4}$ Endocrinology Division, Department of Medicine, Hammoud Hospital University Medical Center, Beirut, Lebanon. ${ }^{5}$ Endocrinology Division, Department of Medicine, Mount Lebanon Hospital and Gharios Medical Center, Beirut, Lebanon. ${ }^{6}$ Endocrinology Division, Department of Medicine, Saint Joseph Hospital, Beirut, Lebanon.

\begin{abstract}
Background: Lebanon is part of the global DISCOVER study, a global, noninterventional, multicentre, prospective study with 3-years of follow-up.

Aims: The aim of this study is to describe real-world clinical practice in terms of type 2 diabetes mellitus (T2DM) disease management and treatment patterns within Lebanon.
\end{abstract}

Methods: Baseline demographic and clinical parameters were captured on a standardized case report form, according to routine clinical practice at each clinical site.

Results: We recruited 348 patients. At the initiation of second-line therapy, mean duration of diabetes was 6.7 [standard deviation (SD) 6.5] years; mean HbAic and fasting plasma glucose levels were 8.5\% (SD 1.6\%) and 178.7 (SD 56.5) mg/dL respectively. Almost half the patients were hypertensive (45.1\%) or had dyslipidaemia (48.6\%). Metformin monotherapy was used as first-line therapy in $56.9 \%$ of the patients and upfront dual therapy in $25 \%$. The primary reason for changing firstline therapy was poor glycaemic control. The main factors in choosing the second-line therapy were efficacy, tolerability and hypoglycaemia.

Conclusion: Clinical inertia was evident in this cohort of patients as they had suboptimal glycaemic control at the time of enrolment and the initiation of second-line therapy. Treatment intensification is required to reduce diabetes-related adverse outcomes.

Keywords: DISCOVER study, type 2 diabetes, oral glucose-lowering agents, 2nd-line treatment, Lebanon

Citation: Azar S; Echtay A; Amm M; Ballout H; Cheaib I, El Nazer H; et al. Characteristics and treatment patterns of patients with type 2 diabetes in Lebanon: the DISCOVER study. East Mediterr Health J. 2021;27(5):509-515. https://doi.org/10.26719/2021.27.5.509

Received: 05/06/19, accepted: 22/06/20

Copyright (c) World Health Organization (WHO) 2021. Open Access. Some rights reserved. This work is available under the CC BY-NC-SA 3.0 IGO license (https://creativecommons.org/licenses/by-nc-sa/3.o/igo)

\section{Introduction}

The worldwide prevalence of type 2 diabetes mellitus (T2DM) is increasing, currently affecting around 425 million patients and is estimated to increase to 629 million patients by 2045 (1). It is well known that patients with T2DM are at high risk of developing micro- and macrovascular complications. The combination of lifestyle modifications and pharmacological treatment is necessary to achieve good glycaemic control, which significantly reduces the risk of both diabetes-related microand macrovascular complications (2-6).

According to the most recent International Diabetes Federation update, the prevalence of diabetes in the Middle East and North Africa region is $12.8 \%$, and $45 \%$ of people living with diabetes in this region are undiagnosed (7). In Lebanon, the prevalence of T2DM is increasing, predominantly due to increases in obesity, an aging population and an increasingly sedentary lifestyle $(8,9)$. In a recent national survey, the prevalence of T2DM was $8.5 \%$ (10). However, this was reported to be higher according to International Diabetes Federation report: in Lebanon, the prevalence of age-adjusted T2DM was reported to be at $12.6 \%$ (11). Therefore, further epidemiologic data are required to provide more accurate information about the incidence and prevalence of the disease, comorbidities, and management patterns of diabetes.

According to international guidelines, T2DM requires comprehensive management to reduce the risk of complications and improve quality of life. However, in many Middle Eastern countries, data on diabetes treatment and outcomes are limited.Additionally, few data have been captured on newer classes of glucose-lowering drugs. The ongoing DISCOVERing Treatment Reality of Type 2 Diabetes in Real World Settings (DISCOVER) study aims to address these knowledge gaps by providing real-world observational data on the use of second- and later-line glucose-lowering therapies in people with T2DM worldwide. DISCOVER (NCT02322762) is a 3-year long, noninterventional, multicentre, observational, longitudinal cohort study with 14391 participants recruited from sites in 37 countries; J-DISCOVER 
(NCTo2226822) is being conducted in Japan with almost 2000 patients recruited (12). The study is designed to provide a worldwide evaluation of the current state of type 2 diabetes treatment. Moreover, DISCOVER will provide information about diabetes and its management and treatment in areas with a high prevalence of diabetes such as China, India and the Middle East and in regions which have not been adequately studied such as the Middle East and Africa (12).

The DISCOVER study's primary objective was to describe disease management patterns and disease evolution over 3 years in patients with T2DM initiating a second-line glucose-lowering therapy. The secondary objectives were to describe patient and treatment characteristics, capture treatment changes, capture outcomes such as achievement of treatment targets (e.g. HbAic, body mass index, blood pressure), incidence of micro- and macrovascular complications, incidence of hypoglycaemic events, patient-reported quality of life, and health care resource use to assess factors associated with treatment choices and those associated with complications (12). In this report, we discuss the results of the baseline characteristics and treatment patterns of the DISCOVER study cohort from Lebanon.

\section{Methods}

In brief, the DISCOVER study is an ongoing, prospective, observational (non-interventional) study of patients with T2DM who are initiating a second-line glucose-lowering therapy. Full details of the rationale, methods and inclusion and exclusion criteria of the study are available elsewhere (12).

Patients $\geq 18$ years of age with T2DM who were starting second-line glucose-lowering therapy (add-on or switching) after failure of first-line oral treatment were eligible and invited to participate in the study. The study was carried out from October 2015 to November 2019. All participants signed an informed consent form. Patients were excluded if they had type 1 diabetes or were receiving injectable agents as a first-line therapy. The study was carried out according to the International Conference on Harmonization of Good Clinical Practice after receiving the appropriate approvals from the ethics committee/institutional review board of each participating site (13). The investigators and the sites were selected based on data provided from peer-reviewed articles, World Health Organization reports, and a national country coordinator, taking into consideration the geographical distribution of the practices within the country and the different types of clinics and hospitals. All potential sites were invited to participate, and the number of sites was in line with the targeted sample size required from Lebanon and the potential recruitment of each site. Data collection was carried out using electronic standardized case report forms at baseline and at future routine visits at approximately $6,12,24$ and 36 months within a window of $4( \pm 2)$ months of the routine followup visits. It is also worth noting that the protocol did not require any mandatory follow-up visits to ensure that the study reflected routine clinical practice. The investigator was able to contact a patient via telephone to obtain the necessary information. The baseline data included socioeconomic and demographic information, vital signs, laboratory values and previous medical history, including diabetes history and complications, comorbidities, firstand second-line glucose-lowering therapy and reasons for change or choice of new therapy (12). Disease diagnosis, patient treatment intensification and the diagnosis of hypertension and hyperlipidaemia were made according to the judgement of the investigators; no guidelines were provided in the trial protocol.

The sample size was calculated based on the criteria that any qualitative variable at a frequency of $5-95 \%$ and with 200 patients should ensure a precision range of $3.0-6.9 \%$ at $95 \%$ confidence in any given group of patients to be analysed, including patients from one country or patients receiving a class of drugs or composite endpoints of microvascular or macrovascular complications (12).

All statistical analyses were performed using the SAS statistical software system. Primary and secondary variables were summarized using descriptive statistics. The descriptive statistics used for the study include mean, median, standard deviation, minimum and maximum for continuous variables and frequency for categorical variables. To assess the association of treatment class at baseline with clinical outcome variables, multivariate Cox models were used. Interim analysis was performed at the baseline and 1-2 years after the last patient was recruited (12).

\section{Results}

Altogether, 348 patients were recruited by 15 different endocrinologists/diabetologists in urban locations within Lebanon; $56.9 \%$ of the patients were male. Patient's mean age was 59.2 [standard deviation (SD) 10.3] years with a mean body mass index of 29.8 (SD 4.6$) \mathrm{kg} / \mathrm{m}^{2}$. The mean duration of diabetes was 6.7 (SD 6.5) years and the mean HbAic and fasting plasma glucose levels were 8.5\% (SD 1.6\%) and 178.7 (SD 56.5) $\mathrm{mg} / \mathrm{dL}$ respectively (Table 1). Around $63 \%$ of patients reported being educated to secondary level or to university/higher level. However, $40 \%$ of the patients were unemployed. The vast majority $(72.4 \%)$ had health insurance coverage. Almost half the patients were hypertensive $(45.1 \%)$ or had dyslipidaemia (48.6\%) and were receiving treatment. Just over $25 \%$ reported being current smokers and $20.1 \%$ reported alcohol use. Diabetes-related micro- and macrovascular complications were documented in $14.1 \%$ and $12.1 \%$ of the patients, respectively (Table 1).

Metformin monotherapy was used as a first-line therapy in $56.9 \%$ of the patients and upfront dual therapy was used in $25.0 \%$ of the patient population (Table 2). As second-line antidiabetic therapy, dual therapy [metformin and dipeptidyl peptidase-4 inhibitors (DPP4i)] was used in $47.4 \%$ of the patients and triple therapy (metformin, sulfonylureas and DPP-4i) in 10.9\%. A 


\begin{tabular}{|c|c|c|}
\hline \multirow[t]{2}{*}{ Parameter } & \multicolumn{2}{|c|}{ Patients $(n=348)$} \\
\hline & No. & $\%$ \\
\hline Sex, male & 198 & 56.9 \\
\hline \multicolumn{3}{|l|}{ Main working status } \\
\hline Employed/self-employed & 182 & 52.3 \\
\hline Not working & 139 & 40.0 \\
\hline Retired & 12 & 3.4 \\
\hline Missing data & 15 & 4.3 \\
\hline \multicolumn{3}{|l|}{ Health insurance coverage } \\
\hline Private & 129 & 37.1 \\
\hline Public/governmental & 84 & 24.1 \\
\hline Mixed & 39 & 11.2 \\
\hline No insurance & 73 & 21.0 \\
\hline Missing data & 23 & 6.6 \\
\hline \multicolumn{3}{|l|}{ Education level (years) } \\
\hline No formal education & 30 & 8.6 \\
\hline Primary (1-6) & 67 & 19.3 \\
\hline Secondary (7-13) & 146 & 42.0 \\
\hline University/higher education $(13+)$ & 74 & 21.3 \\
\hline Missing data & 31 & 8.9 \\
\hline \multicolumn{3}{|l|}{ Tobacco smoking } \\
\hline Non-smoker & 210 & 60.3 \\
\hline Ex-smoker & 43 & 6.8 \\
\hline Current smoker & 91 & 26.2 \\
\hline Missing data & 23 & 6.6 \\
\hline \multicolumn{3}{|l|}{ Alcohol drinking } \\
\hline Lifetime abstainer & 273 & 79.4 \\
\hline Former drinker & 2 & 0.6 \\
\hline Drinker & 69 & 20.1 \\
\hline Missing data & 4 & 1.2 \\
\hline Hypertension & 157 & 45.1 \\
\hline Hyperlipidaemia & 169 & 48.6 \\
\hline Any microvascular complication & 49 & 14.1 \\
\hline \multirow[t]{2}{*}{ Any macrovascular complication } & 42 & 12.1 \\
\hline & Mean & SD \\
\hline Age (years) & 59.2 & 10.3 \\
\hline $\mathrm{HbAl}_{c}(\%)$ & 8.5 & 1.6 \\
\hline Fasting glucose (mg/dL) & 178.7 & 56.5 \\
\hline Duration of diabetes (years) & 6.7 & 6.5 \\
\hline Body mass index $\left(\mathrm{Kg} / \mathrm{m}^{2}\right)$ & 29.8 & 4.6 \\
\hline Systolic blood pressure (mmHg) & 133.0 & 14.4 \\
\hline Diastolic blood pressure (mmHg) & 77.5 & 8.1 \\
\hline Low density lipoprotein cholesterol (mg/dL) & 109.2 & 38.6 \\
\hline
\end{tabular}

target goal at the time of initiation of the new treatment was set in $63.2 \%$ of the patients. Nine patients reported that they experienced a major hypoglycaemia episode prior to initiating the second-line therapy in the year prior to the study. The main reason for changing the first-line therapy was lack of efficacy (Table 3). The main factors for choosing thesecond-linetherapywereefficacy,tolerability, and hypoglycaemia (Table 4).

Antihypertensive and lipid lowering drug therapy were prescribed as concomitant medications in $49.1 \%$ and $51.7 \%$ of the patients respectively (Table 5). Angiotensin converting enzyme (ACE) inhibitors or angiotensin receptor blockers (ARBs) and statins were the most frequentlyusedantihypertensiveandlipidloweringagents in $31.9 \%$ and $45.4 \%$, respectively. Aspirin had low use, $16.4 \%$, in this diabetes patient population.

\section{Discussion}

The DISCOVER study is an ongoing global comprehensive programme which aims to report treatment patterns after the initiation of second-line glucose-lowering thera-

\begin{tabular}{|c|c|c|}
\hline Treatment & No. & $\%$ \\
\hline \multicolumn{3}{|c|}{ First-line therapy } \\
\hline Met (Mono) & 198 & 56.9 \\
\hline SU (Mono) & 22 & 6.3 \\
\hline DPP-4i (Mono) & 5 & 1.4 \\
\hline Other (Mono) & 3 & 0.9 \\
\hline Met+SU (Dual) & 49 & 14.1 \\
\hline Met+DPP-4i (Dual) & 32 & 9.2 \\
\hline Met+other (Dual) & 2 & 0.6 \\
\hline Other dual therapy & 3 & 0.9 \\
\hline Met+SU+DPP-4i (Triple) & 21 & 6.0 \\
\hline Met+SU+TZD (Triple) & 1 & 0.3 \\
\hline Other triple therapy & 8 & 2.3 \\
\hline 4 or $4+$ therapy & 4 & 1.1 \\
\hline \multicolumn{3}{|c|}{ Second-line therapy } \\
\hline Met (Mono) & 3 & 0.9 \\
\hline SU (Mono) & 5 & 1.4 \\
\hline DPP-4i (Mono) & 14 & 4.0 \\
\hline SGLT-2i (Mono) & 7 & 2.0 \\
\hline Other monotherapy & 5 & 1.4 \\
\hline Met+SU (Dual) & 16 & 4.6 \\
\hline Met+DPP-4i (Dual) & 165 & 47.4 \\
\hline Met+SGLT-2i (Dual) & 6 & 1.7 \\
\hline Met+other (Dual) & 5 & 1.4 \\
\hline SU+TZD (Dual) & 4 & 1.1 \\
\hline Other dual therapy & 9 & 2.6 \\
\hline Met+SU+DPP-4i (Triple) & 38 & 10.9 \\
\hline Met+SU+TZD (Triple) & 11 & 3.2 \\
\hline Other triple therapy & 21 & 6.0 \\
\hline 4 or $4+$ therapy & 33 & 9.5 \\
\hline Insulin (may also receive oral therapy) & 6 & 1.7 \\
\hline
\end{tabular}

MET = metformin,$S U$ = sulfonylurea, $D P P-4 i$ = dipeptidyl peptidase 4 inhibitors, TZD = thiazolidinedione, SGLT-2i = sodium-glucose cotransporter 2 inhibitors . 
Table 3 Reasons for changing first-line therapy in the study sample: 348 patients aged $\geq 18$ years with T2DM who were starting second-line glucose-lowering therapy, Lebanon, 2015-2019

\begin{tabular}{lc} 
Reason for changing first-line therapy & $\begin{array}{c}\text { No. (\%) of } \\
\text { patients }\end{array}$ \\
\hline Lack of efficacy & $315(90.5)$ \\
Weight gain & $27(7.8)$ \\
Hypoglycaemic event & $18(5.2)$ \\
Side effect & $9(2.6)$ \\
Physician preference & $7(2.0)$ \\
Patient convenience/comfort & $5(1.4)$ \\
Developed acute disease & $4(1.1)$ \\
Affordability & $2(0.6)$ \\
Developed chronic disease & $1(0.3)$ \\
\hline
\end{tabular}

py in patients with T2DM. This baseline report represents the subgroup of T2DM patients from Lebanon, and provides an overview of the real-world clinical practice and treatment trends of patients with T2DMin urban locations within Lebanon.

Ourparticipantswerehighlyeducated, butthereported rateofunemploymentwashigh.Ahighunemploymentrate has been shown to predispose patients to T2DM and poor glycaemic control (14). In a 2013 study, Azar et al. showed that a large number of Lebanese patients with T2DM had inadequate glycaemic control or were poorly followedup (15). The current DISCOVER study demonstrated that baseline glycaemic level was suboptimal with a long duration of diabetes from the initial diagnosis. Some patients were reported to be hypertensive or dyslipidaemic and yet were not receiving treatment, which increases their cardiovascular risk, despite the fact that $34.5 \%$ of the Lebanese subgroup in this study were on dual, triple or even quadruple antidiabetic drug therapy as an initial treatment. This is explained by the progressive nature of T2DM over time and yet there was a delay in treatment intensification to achieve optimal glycaemic control.

Table 4 Reasons for choosing a second-line therapy in the study sample: 348 patients aged $\geq 18$ years with T2DM who were starting second-line glucose-lowering therapy, Lebanon, 2015-2019

\begin{tabular}{lc} 
Reason & No. (\%) of patients \\
Efficacy & $273(78.4)$ \\
Tolerability & $85(24.4)$ \\
Hypoglycaemia & $84(24.1)$ \\
Weight gain & $66(19.0)$ \\
Patient convenience/comfort & $30(8.6)$ \\
Cost & $24(6.9)$ \\
Patient request & $12(3.4)$ \\
Access reason & $11(3.2)$ \\
Other & $22(6.9)$ \\
\hline
\end{tabular}

However, the second-line glucose-lowering treatment showed that the diabetologists were keen on adding further drug therapy to achieve better glycaemic control. Dual, triple, and quadruple or more antidiabetic drug therapies were utilized in $76.3 \%, 20.1 \%$, and $9.5 \%$, respectively. HbA1c levels will be monitored in future visits over the 3-year period of the study as part of the routine clinical practice and the study protocol. This will provide valuable clinical information on the new combination of drug therapy and whether it has a favourable effect on HbAlc levels, adverse events, and micro- and macro-complications in these patients.

The drug therapy that was utilized the most as a firstand second-line therapy was metformin monotherapy and metformin and DPP-4 inhibitors combination, respectively. Sulfonylurea use was relatively low as a first-line treatment as monotherapy. However, the use of sulfonylureas was greater in combination with other antidiabetic agents despite the fear of hypoglycaemia and/ or weight gain. It is worth noting that the vast majority of the patients in Lebanon had health care coverage with few formulary restrictions, which enables physicians to freely prescribe antidiabetic medications.

Metformin, in conjunction with lifestyle changes, is recommended as a first-line therapy for patients with T2DM by most clinical guidelines (16-21). There is preferential recommendation for the use of novel antidiabetic agents over the traditional classes in multiple clinical settings $(20,21)$. The DISCOVER study is considered essential because it generates real-world data that reviews trends in prescribing practices in different clinical settings and provides relevant data on diabetes management and clinical outcomes.

\begin{tabular}{lc}
\hline $\begin{array}{l}\text { Table } 5 \text { Concomitant medications prescribed in the study } \\
\text { sample: } \mathbf{3 4 8} \text { patients aged } \geq \mathbf{1 8} \text { years with T2DM who were } \\
\text { starting second-line glucose-lowering therapy, Lebanon, } \\
\text { 2015-2019 }\end{array}$ No. (\%) of \\
Concomitant medications & $171(49.1)$ \\
Concomitant antihypertensive drugs & $111(31.9)$ \\
ACEIs \& ARBs & $63(18.1)$ \\
Beta-blockers & $23(6.6)$ \\
Calcium channel antagonists & $36(10.3)$ \\
Diuretics & $11(3.2)$ \\
Other antihypertensive drugs & $180(51.7)$ \\
Concomitant lipid-lowering drugs & $76(21.8)$ \\
\hline High intensity statins & $82(23.6)$ \\
Low intensity statins & $37(10.6)$ \\
Fibrate & $0(0.0)$ \\
Niacin & $0(0.0)$ \\
Other lipid-lowering drugs & $66(19.0)$ \\
Concomitant antiplatelet drugs & $57(16.4)$ \\
Aspirin & $12(3.4)$ \\
Clopidogrel & \\
\hline ACEI = angiotensin converting enzyme inhibitors. & \\
ARBs = angiotensin receptor blockers. &
\end{tabular}


Our study may have some limitations, for instance patient and investigator selection bias. The investigators were carefully selected to be representative of the management of T2DM in Lebanon but the study did not include primary care physicians, perhaps due to challenges in infrastructure and/or the lack of experience in running clinical research. Patient selection bias could not be excluded because most of the patients were reported to have secondary or higher education, demonstrating that they were more educated and willing to participate in this observational study. In addition, we feel that cardiovascular risk factors such as smoking were under-reported by the participants and caution should be exercised when interpreting the results.

\section{Conclusions}

The baseline data of this cohort of the DISCOVER study from Lebanon demonstrated that there was a delay in the intensification of treatment and patients had suboptimal glycaemic control. The reasons could be attributed to several factors, which need to be further explored. An integrated approach to the management of T2DM considering metabolic, cardiovascular and renal risks is warranted to reduce the risk of micro- and macrovascular complications and is emphasized in recent international guidelines for the management of the disease (16-21). More efforts are needed to educate health care providers on strategies aimed at early intervention to ensure timelier and better control of glycaemic parameters and cardiovascular risk factors to delay or prevent T2DM-related complications.

\section{Acknowledgement}

We would like to thank Dr Mazen Matalka from Advanced Healthcare Solutions for his help in writing the manuscript.

Funding: The DISCOVER study was fully sponsored by AstraZeneca.

Competing interests: All authors have received payments from AstraZeneca for speaker, advisor and investigator activities.

\section{Caractéristiques et modes de traitement des patients atteints de diabète de type 2 au Liban : l'étude DISCOVER}

\section{Résumé}

Contexte: Le Liban fait partie de l'étude mondiale DISCOVER, une étude prospective internationale, non interventionnelle et multicentrique assortie d'un suivi de trois ans.

Objectifs : La présente étude a pour objectif de décrire la pratique clinique réelle en termes de prise en charge du diabète de type 2 et de modes de traitement au Liban.

Méthodes : Les paramètres démographiques et cliniques de référence ont été consignés dans un cahier d'observation standardisé, conformément à la pratique clinique habituelle de chaque site clinique.

Résultats : Nous avons recruté 348 patients. Au début du traitement de seconde interntion, la durée moyenne du diabète était de 6,7 ans [écart type (ET) 6,5] ; les taux moyens d'hémoglobine glyquée et de glucose plasmatique à jeun étaient respectivement de $8,5 \%(E T)$ (1,6 \%) et 178,7 (ET 56,5) $\mathrm{mg} / \mathrm{dl}$. Près de la moitié des patients étaient hypertendus $(45,1 \%)$ ou présentaient une dyslipidémie $(48,6 \%)$. La metformine en monothérapie a été utilisée comme traitement de première intention chez $56,9 \%$ des patients et une bithérapie initiale chez $25 \%$ des patients. La principale raison du changement de traitement de première intention était un mauvais contrôle glycémique. Les principaux facteurs de choix du traitement de deuxième intention étaient l'efficacité, la tolérance et l'hypoglycémie.

Conclusions : L'inertie clinique était évidente dans cette cohorte de patients car leur contrôle glycémique était sousoptimal au moment de l'inscription et de la mise en route du traitement de seconde intention. Une intensification du traitement est nécessaire pour réduire les effets indésirables liés au diabète. 
"DISCOVER" خصائص وأنهاط علاج مرضى السُكّريّ من النمط 2 في لبنان: دراسة

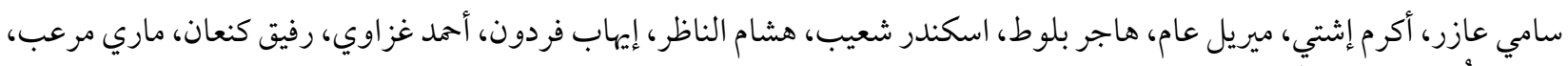
يوسف عُبيد، منذر صالح، سارية واكيم، عامئ ماميل زين الخلاصة

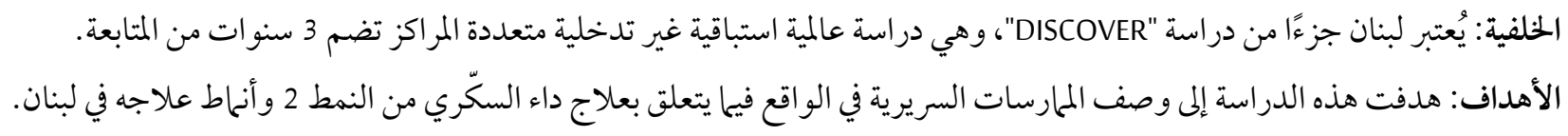

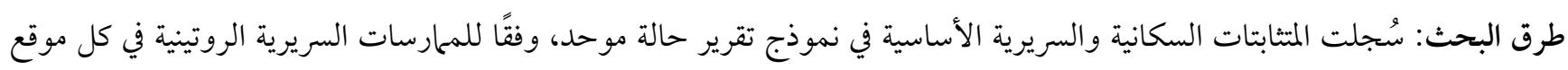
سريري.

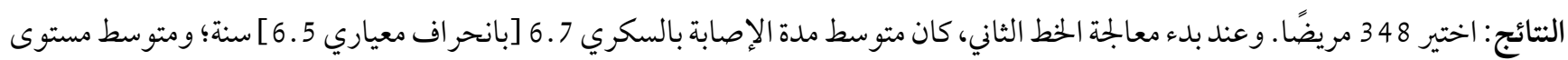

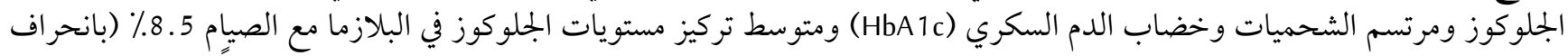

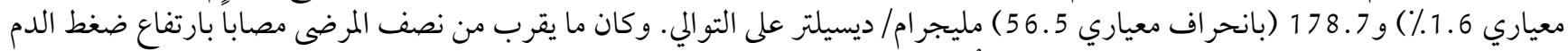

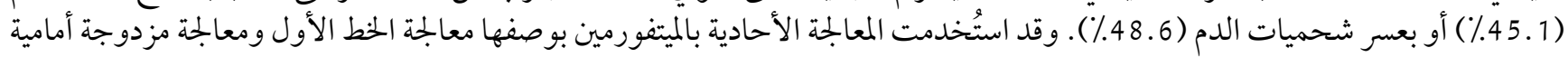

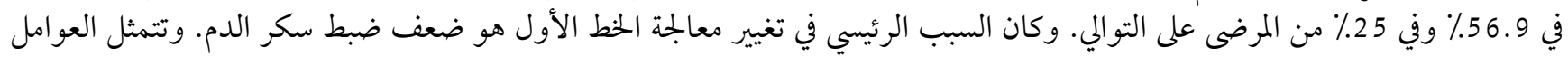

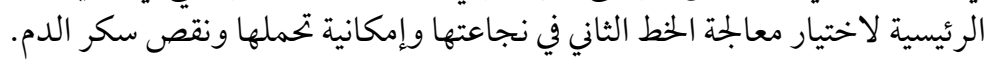

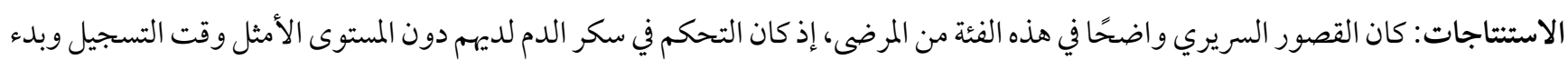

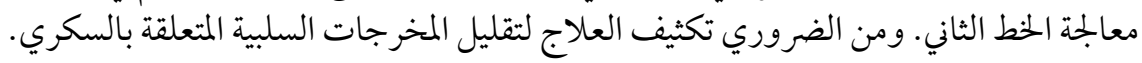

\section{References}

1. IDF Diabetes Atlas, 8th ed. Brussels, Belgium: International Diabetes Federation, 2017. (http://www.diabetesatlas.org, accessed 28 May 2018).

2. Ray KK, Seshasai SR, Wijesuriya S, Sivakumaran R, Nethercott S, Preiss D, et al. Effect of intensive control of glucose on cardiovascular outcomes and death in patients with diabetes mellitus: a meta-analysis of randomized controlled trials. Lancet. 2009;373:1765-72. doi:10.1016/So140-6736(09)60697-8

3. Holman RR, Paul SK, Bethel MA, Matthews DR, Neil HA. 10-Year follow-up of intensive glucose control in type 2 diabetes. N Engl J Med. 2008;359:1577-89. doi:10.1056/NEJMoa0806470

4. Intensive blood-glucose control with sulfonylureas or insulin compared with conventional treatment and risk of complications in patients with type 2 diabetes (UKPDS 33). Lancet. 1998;352:837-53. PMID:9742976

5. Stratton IM, Adler AI, Neil HA, Matthews DR, Manley SE, Cull CA, et al. Association of glycaemia with macrovascular and microvascular complications of type 2 diabetes (UKPDS 35): prospective observational study. BMJ. 2000;321:405-12. doi:10.1136/ bmj.321.7258.405

6. ADVANCE Collaborative Group, Patel A, MacMahon S, Chalmers J, Neal B, Billot L, Woodward M, et al. Intensive blood glucose control and vascular outcomes in patients with type 2 diabetes. N Engl J Med. 2008;358:2560-72. doi:10.1056/NEJMoa0802987

7. Diabetes in MENA. Brussels: International Diabetes Federation; 2019 (https://www.idf.org/our-network/regions-members/middle-east-and-north-africa/diabetes-in-mena.html, accessed 2 December, 2020).

8. Sibai A, Sen K, Baydoun M, Saxena P. Population ageing in Lebanon: current status, future prospects and implications for policy. Bull World Health Organ. 2004 March; 82(3):219-25. PMID: 15112011

9. Ghassibe-Sabbagh M, Deeb M, Salloum AK, Mouzaya F, Haber M, Al-Sarraj Y, et al. Multivariate epidemiologic analysis of type 2 diabetes mellitus risks in the Lebanese population. Diabetol Metab Syndr. 2014;6:89. doi:10.1186/1758-5996-6-89

10. Costanian C, Bennett K, Hwalla N, Assaad S, Sibai AM. Prevalence, correlates and management of type 2 diabetes mellitus in Lebanon: findings from a national population-based study. Diabetes Res Clin Pract. 2014 Sep;105(3):408-15. doi:10.1016/j.diabres.2014.06.005

11. Middle East and North Africa. IDF Diabetes Atlas, 8th ed. Brussels: International Diabetes Federation; 2017 (www.diabetesatlas. org/component/attachments/?task=download\&id=264, accessed 28 May 2018).

12. Ji L, Bonnet F, Charbonnel B, Gomes MB, Kosiborod M, Khunti K, et al. Towards an improved global understanding of treatment and outcomes in people with type 2 diabetes: rationale and methods of the DISCOVER observational study program. J Diabetes Complications. 2017 Jul;31(7):1188-96. doi:10.1016/j.jdiacomp.2017.03.011

13. Dixon JR Jr. Conference on Harmonization Good Clinical Practice guideline. Qual Assur. 1998 Apr-Jun;6(2):65-74.

doi:10.1080/105294199277860 
14. Rautio N, Varanka-Ruuska T, Vaaramo E, Palaniswamy S, Nedelec R, Miettunen J, et al. Accumulated exposure to unemployment is related to impaired glucose metabolism in middle-aged men: A follow-up of the Northern Finland Birth Cohort 1966. Prim Care Diabetes. 2017;11(4):365-72. doi:10.1016/j.pcd.2017.03.010

15. Azar ST, Malha LP, Zantout MS, Naja M, Younes F, Sawaya MT. Management and control of patients with type 2 diabetes mellitus in Lebanon: results from the International Diabetes Management Practices Study (IDMPS). J Med Liban. 2013 JulSep;61(3):127-31. doi:10.12816/0001439

16. American Diabetes Association. Pharmacologic approaches to glycemic treatment: standards of medical care in diabetes-2018. Diabetes Care. 2018. Jan;41(Suppl 1):S73-S85. doi:10.2337/dc18-Soo8.

17. Ryden L, Grant PJ, Anker SD, Berne C, Cosentino F, Danchin N, et al. ESC Guidelines on diabetes, pre-diabetes, and cardiovascular diseases developed in collaboration with the EASD: the Task Force on diabetes, pre-diabetes, and cardiovascular diseases of the European Society of Cardiology (ESC) and developed in collaboration with the European Association for the Study of Diabetes (EASD). Eur Heart J. 2013;34:3035-87. doi:10.1093/eurheartj/eht108

18. Inzucchi SE, Bergenstal RM, Buse JB, Diamant M, Ferrannini E, Nauck M, et al. Management of hyperglycaemia in type 2 diabetes, 2015: a patient-centered approach. Update to a position statement of the American Diabetes Association and the European Association for the Study of Diabetes. Diabetes Care 2015 Jan;38(1):140-9. doi:10.2337/dc14-2441

19. Garber AJ, Abrahamson MJ, Barzilay JI, Blonde L, Bloomgarden ZT, Bush MA, et al. AACE/ACE comprehensive diabetes management algorithm 2015. Endocr Pract. 2015;21:438-47. doi: 10.4158/EP15693.CS

20. Garber AJ, Abrahamson MJ, Barzilay JI, et al. Consensus statement by the American Association of Clinical Endocrinologists and American College of Endocrinology on the Comprehensive Type 2 Diabetes management algorithm-2016 Executive summary. Endocr Pract. 2018 Jan;24(1):91-120. doi:10.4158/CS-2017-0153

21. Davies MJ, D’Alessio DA, Fradkin J, et al. Management of hyperglycaemia in type 2 diabetes, 2018. A consensus report by the American Diabetes Association (ADA) and the European Association for the Study of Diabetes (EASD). Diabetologia. 2018 Dec;61(12):2461-98. doi:10.1007/s00125-018-4729-5 